\title{
Case study: the simulation modelling of selected activity in a warehouse operation
}

\author{
Janka Saderova ${ }^{1}$ (D) Andrea Rosova ${ }^{1}$ (D) $\cdot$ Annamaria Behunova $^{2}$ (D) Marcel Behun $^{2}$ (D) Marian Sofranko $^{2}$ (D) \\ Samer Khouri ${ }^{2}$ iD
}

Accepted: 23 February 2021 / Published online: 16 March 2021

(c) The Author(s) 2021

\begin{abstract}
The paper deals with the simulation of selected activities in the warehouse. Routine logistics activities are the receipt of the goods, the control of the goods, and the goods' storage in the warehousing system on the side of the entry into the warehouse. On the output side, these are activities such as picking, packing and shipping. The economy of warehouse operations depends on the efficiency of the logistics activities performed and on deployed the technical means. The paper's main goal is to present a created simulation model for a selected warehouse activity-receipt of goods into the warehouse. This operation involves unloading the goods from the trucks, moving them to the physical receipt, where the quantitative and qualitative control of the goods is performed (acceptance of goods). An analysis of this activity preceded the creation of the simulation model under operating conditions. The research was performed by observing and measuring the forklift's work cycle, which unloaded pallets from the trucks. The obtained data from the analysis were the input to the simulation model. The EXTENDSIM8 simulation system was used to create a simulation model. The several experiments were performed on the model after its creating and verifying the functionality. The paper evaluates 3 experiments and analyzes their results. The main benefit, novelty, of the article is the simulation of a selected activity for a specific company's conditions. The experiments results are a reasonable basis for the creation of an operational tool for the company.
\end{abstract}

Keywords Analysis · Activity $\cdot$ Simulation $\cdot$ Experiments $\cdot$ Results

\section{Introduction}

Andrea Rosova

andrea.rosova@tuke.sk

Janka Saderova

janka.saderova@tuke.sk

Annamaria Behunova

annamaria.behunova@tuke.sk

Marcel Behun

marcel.behun@tuke.sk

Marian Sofranko

marian.sofranko@tuke.sk

Samer Khouri

samer.khouri@tuke.sk

1 Faculty of Mining, Ecology, Process Control and Geotechnologies, Institute of Logistics and Transport, Technical University of Kosice, Kosice, Slovakia

2 Faculty of Mining, Ecology, Process Control and Geotechnologies, Institute of Earth Resource, Technical University of Kosice, Kosice, Slovakia
The storage process, as one of the logistics processes, currently holds an irreplaceable position in logistics systems in companies and in the supply chain. A common goal of warehouse operation is to satisfy the customer demand and utilize the resources effectively to ensure the perfect operation of a warehouse [1].

The economy of warehouse operations depends on the efficiency of the logistics and activities performed and on deployed the technical means. Routine logistics activities are the receipt of the goods, the control of the goods and the storage of the goods in the warehousing system on the side of entry into the warehouse. On the output side, these are activities such as picking and shipping. The issue of warehousing as a whole is extensive and several authors address it. Some authors deal with warehousing comprehensively. Some authors include that as a chapter in their publications. However, there are many publications that 
describe and solve isolated warehousing problems. The most frequently solved topics and problems are: warehouse design and performance evaluation [2,3], design and control of warehouse order picking [4], design of a storage system by applying the logistics principles [5], warehouse layout problems [6], warehouse process strategies [7], and device selection problem e.g. transport trucks, their number and others [8]. The authors use various available tools and techniques to solve problems: calculations, modelling, numerical simulation, computer simulation, etc. [9].

The use of simulation modeling as a scientific method in research and practice is widespread. The benefits of using a simulation modeling approach include financial, time material and energy savings, as well as streamlining activities in practice [10]. Currently, the simulation models are relatively widely used, which authors use to solve mainly problems related to transport, handling, production processes and ecology [11-14]. Nowadays, several simulation tools are used for computer simulation such as Witness [15], Technomatics Plan Simulation [16, 17], Extend [18], FlexSim [19] Arena [13] SimMin [14] and others.

\section{Literature review and methodology}

Understanding the principles of simulation and knowledge of simulation building blocks, their properties, and their use is essential to creating any simulation model, mostly if it corresponds to the system's current vision and the model creator [20]. Continuous change in society increases the demand for more efficient processes. It puts pressure on all manufacturing and non-manufacturing companies, using different approaches to effective team building, automation and robotics, and effective management. As the development and implementation of warehousing logistics expanded, companies found that up to $40 \%$ of costs in this area could only be saved by efficiently managing and streamlining material flows without the real need to purchase new equipment [21, 22]. The development of advanced simulation systems has opened up new possibilities and significantly supported the trend to rationalize warehousing activities, reducing costs and improving business performance [23].

However, simulation is not a tool for obtaining an optimal solution but a tool that allows you to test different decision outputs on a simulation model. Such a model makes it possible to perform various experiments to evaluate, analyze and determine the solution's parameters, which can then be used in a real system. Risk factors can be examined in advance and identified by "exchanging" the ongoing simulation model to monitor system performance and behavior, then review the system's future behavior and any problems and obstacles after applying the required changes. Can be removed in advance. Process animations provide better clarity and visibility of processes without exposing themselves to the risk of damaging the real logistics system in real life by repeated experimentation. Such understanding and knowledge can then prevent errors and shortcomings to avoid possible failures [24]. Process simulation models are a very effective tool for identifying obstacles during the process and improving process parameters. Theoretical knowledge (simulation technique, specific simulation systems) and practical experience (description of the system, its elements and their mutual interactions and connections) are needed for the development of a correct simulation model [25]. The course of the simulation must be monitored at each stage. It is possible to determine the impacts on the system's overall function from the changes that occur at the output of the simulation model. The need for simulation models is based on the possibility of experimenting with the system without interfering with the real system [26]. The model allows you to test several process variants, find optimal process conditions and design new process settings without the need for additional investment. Relevant changes can significantly impact the profitability of production, the company's market position, and customer satisfaction [27].

The main goal of the paper is to present a created simulation model for a selected warehouse activity-receipt of goods into the warehouse. The EXTENDSIM8 simulation system was used to create the simulation model.

\subsection{Characteristics of the activity: receipt of goods in the warehouse}

The task of the warehouse is to store the goods or to arrange them and prepare them for removal from storage at the required time, in the required quantity and quality. This process is carried out using logistic activities. Warehousing activities perform the basic functions: transfer of goods, storage of goods and collection, processing, transmission of information on warehousing activities. The basic logistics activities in the warehouse include: the receipt of the goods, the control of the goods and the storage of the goods in the warehousing system, picking and shipping [23]. This article will present a simulation model for receiving goods into a warehouse.

The logistics activity "receipt of goods" involves several operations [23]:

- Addition of a vehicle to the point of unloading.

- The first phase of the receipt of the goods-control of documents, "Order versus packing list, check the integrity of the delivered goods and supplies of goods. 
- Unloading and transport of goods to the place of receipt (the goods are most often in the form of a pallet unit).

- The second phase of income, which includes a quantitative and qualitative controls, the complexity of supply, the receipt card issued by delivery letter recorded irregularities.

- Transport of goods from place of receipt to take the place of destination (directly to the store to place waiting area prior to the storage, transfer of goods without storage (cross-docking).

\subsection{Application of computer simulation}

Simulation is a research method where we replace the object of study with a model. We make experiments on the created model with the intention to accumulate and later use information about the real system [24, 26].

The simulation of the selected logistics activity consists of several steps. The basic steps are described in the following points and shown in Fig. 1 [26, 27].

A: Identification of the system and its graphical interpretation for the needs of a simulation model creation. A graphical representation of the system is created.

B: Creating a simulation model by the selected simulation tool. Currently, simulation packages are used for creating a simulation, which facilitate the work of creating a model. Their advantage is graphic symbolism, creation of statistics, 2D or 3D animation and flexibility both when changing the model itself and changing the input data.

C: Simulation of experiments, in which the input parameters of the simulation model are changed. The

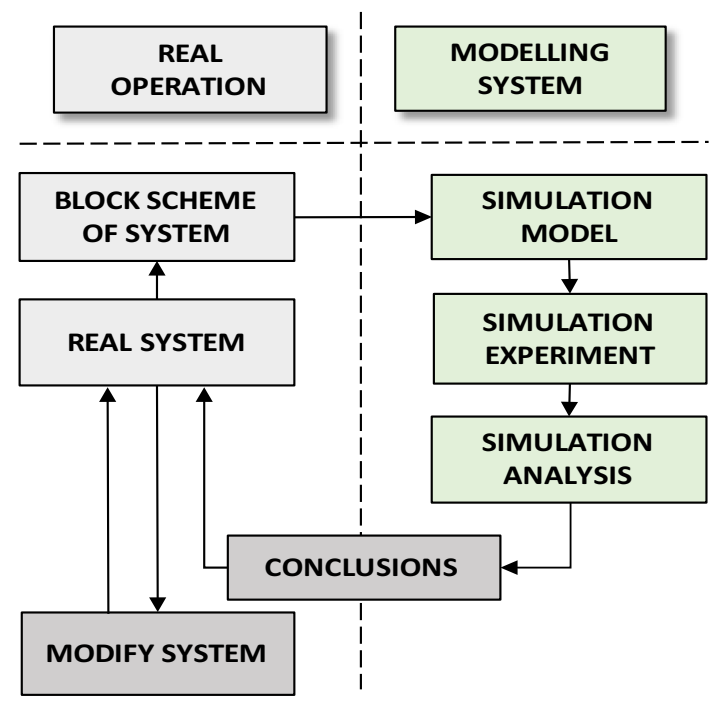

Fig. 1 Simple modelling methodology. Source: author task of the experiments is to see changes in the output parameters of the system.

D: Analysis of simulation results and recommendations. Outputs from individual experiments (statistical parameters, performance parameters and graphical outputs) are used for analysis and behavior of the system under changed conditions. These results need to be interpreted and used correctly.

EXTENDSIM8 simulation tool was used in this study, which is based on discrete event simulation principles.

\section{Research results}

The simulation was applied to the selected operation-the entrance warehouse of the production company. The materials entering the production process are located in the warehouse. On the side of entering the warehouse, two logistics activities are performed.

The first logistics activity is the receipt of goods into the warehouse. In addition to the vehicle's delivery, this activity consists of the operations of unloading pallets and moving them to the place of physical reception. Quantitative and qualitative control of goods is performed at the given place. After quantitative control (order versus delivery note, the integrity of the delivered goods), the warehouse manager confirms the necessary documents and airs them to the vehicle's driver. A quality controller performs quality control. After checking the quality of the goods, before storage, the goods are marked with a label that contains the number of goods on the pallet, the product code under which the entire storage and production process accompanies it, detailed description of the goods, code for scanning goods during storage and removal. A simple scheme of activity is shown in Fig. 2.

The second activity is the storage of goods in the warehouse.

The placement of pallets in the storage system is movable; the storage position is determined randomly.

These two activities are carried out only daily from 10 am to $2 \mathrm{pm}(240 \mathrm{~min})$. One forklift is in operation.

The simulation model is created for the first logistical efficiency: receipt of goods in the warehouse.

For creating and filling the simulation model for the relevant data, an analysis was performed for the first logistics activity. The analysis was performed by observing and measuring the time image of the forklift truck's work cycle.

The observation was performed over 22 working days. Observation results:

- number of vehicles put up for unloading during the given period-72 pieces, 
Fig. 2 Simple scheme of activity. Source: author

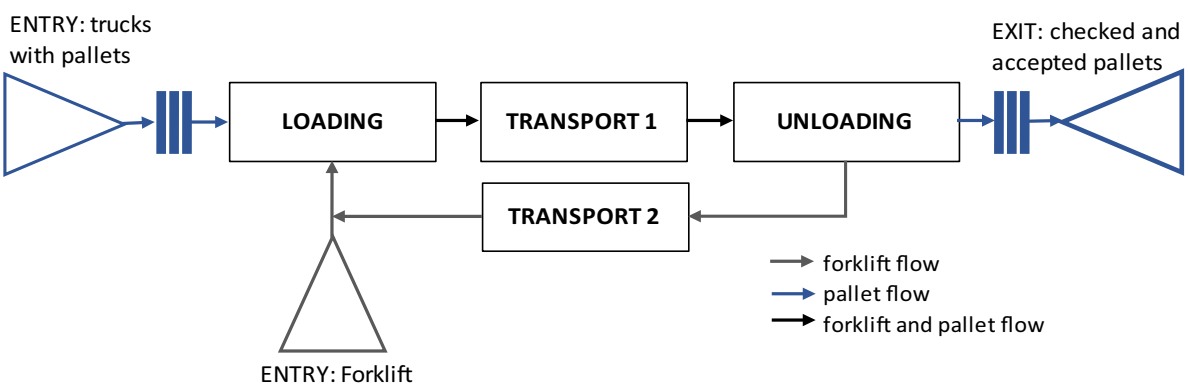

- the average number of vehicles put up for unloading in 1 day is 3.3 ,

- the average number of vehicles for each day of the week: Monday 5 pcs, Tuesday 4 pcs, Wednesday 4 pcs, Thursday 2 pcs, Friday 3 pcs,

- the number of pallets in vehicles from 5 to 32 pcs.

The measurement of the work cycle during the operation was performed for two working days. Partial duty cycle times, as well as full duty cycle times, were measured. The measurements showed

- pallet forklift loading time in 3-5 s intervals,

- pallet truck travel time from loading to unloading 10-20 s,

- time of unloading the pallet at the place of unloading $3-5 \mathrm{~s}$,

- driving time of trucks back to the place of loading $10-15 \mathrm{~s}$,

- duty cycle time $25-43 \mathrm{~s}$.

The data obtained from the observation and measurement of the work cycle were the input data to the created simulation model.

\subsection{Simulation model of selected logistics activity in warehouse}

As it was stated above, the simulation model was created in EXTENDSIM8. The simulation model is created by blocks that are connected with junctions, which determine the direction of the flows (flow of pallets, flow of tracks). Each used block represents the part of the process or operation in the simulation model. The blocks have its unique icon and name there expresses its basic usage within the model $[22,23]$.

The created simulation model is the model of discrete simulation created from blocks taken from the "Discreet Event" and "Plotter" libraries, Fig. 3. Print screen of the created simulation model shows Fig. 4.

The simulation program uses the "Executive" block, which is necessary for the operation of the simulation and for creating the features necessary to distinguish items. The block "Create" creates items or values randomly or by scheduled. The block "Queue"(block operating on the FIFO principle), represents the queue of requirements.

The block "Set" determines each request that passes the preset parameters and proper-ties in the block. The block "Display Value" displays the value on the input connector at each step of the simulation. The block "Batch" is used to connect several inputs with only one output. The block "Resource Item" provides elements that will be used in simulations. The block "Activity" represents the individual activities of the system.

The block "Transport" moves items from one block to another. Has dialog settings for defining haw fast and haw far the item moves. The block "Unbatch" produces several individual elements from one input. The block "Exit" passes items out of the simulation. The total number of items absorbed by this block is reported in its dialog and at the value output connectors. The block "Discrete Event" draws graphs of the simulation performance from the input values and it writes the values of the monitored inputs to a table.

\subsection{Description of the main parts of the simulation model and its settings}

To put blocks on the modelling area of a particular simulation system is no problem. The problem is to give a logical sequence for the connection of the blocks and set the parameters of the blocks so that they correspond to the real factual system [22].

The „Create Trucks entry-Queue 1-Set-Queue 2Display Value" blocks, Fig. 5. Trucks entry represents arrive of the trucks with the loaded palettes. Intervals are set according to the average number of arrivals of camions for one shift, obtained from the analysis. Queue 1 represents the queue of the trucks waiting to be unloaded. The Set block assigns "Item quantity" to incoming trucks. It is necessary in the models, because we cannot determine in advance how many pallets there are in the trucks. Values from the "Random Number" block enter the Set block. The set value is the minimum and maximum number of pallets in the trucks, Fig. 6. Block „Queue“ represents the number 


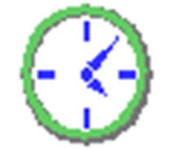

Executive

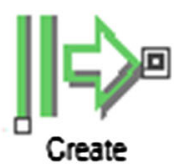

Create
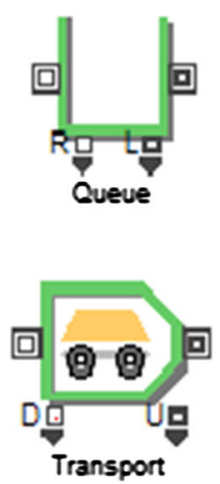
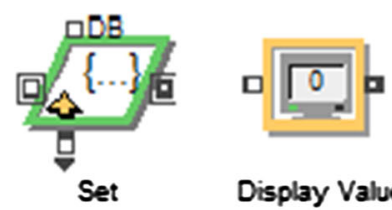

Display Value

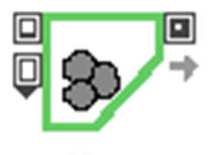

Batch

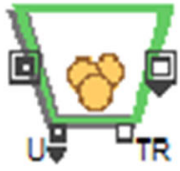

Resourse Item

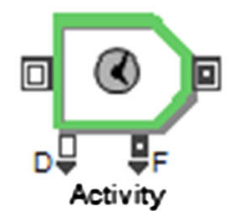

Fig. 3 Blocks of EXTENDSIM 8 simulation program. Source: author
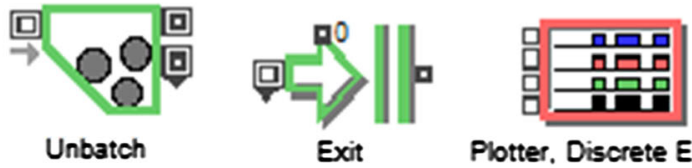

Plotter. Discrete Event

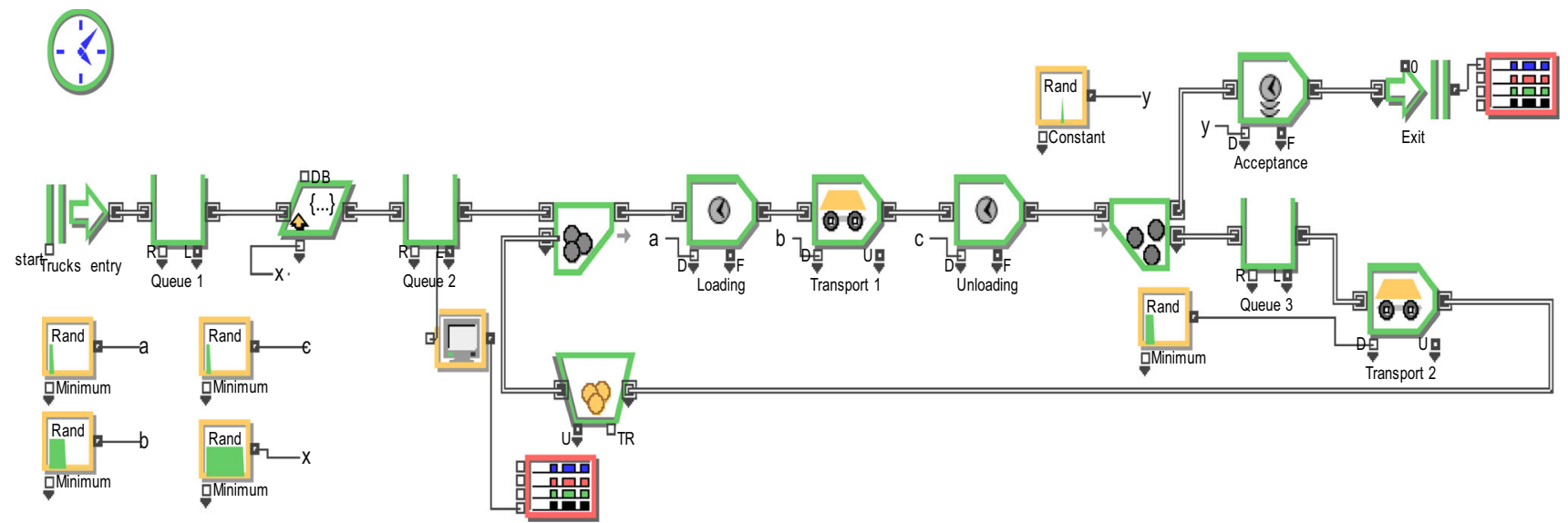

Fig. 4 Print screen of the created simulation model. Source: author

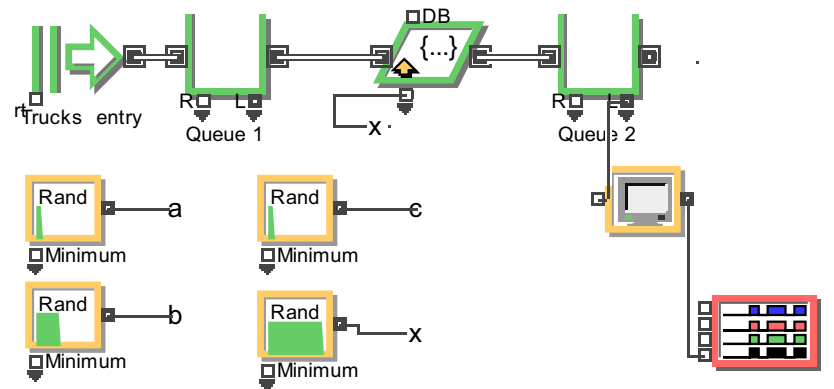

Fig. 5 Blocks "Create Camions/Tracks entry-Queue 1-SetQueue 2-Display Value". Source: author

of pallets in the truck. Display Value displays the value actual the number of pallets in the truck.

The blocks "Resource Item-Bach", Fig. 7, in this section, the connection of the forklift truck to the pallet is connected. The forklift enters the process from the Resource Item block and connects to the pallet in the Batch block, Fig. 8. They continue into the model as a one.

The "Activity Loading-Transport Transport 1-Activity Unloading" blocks, Fig. 9 represent the following operations:

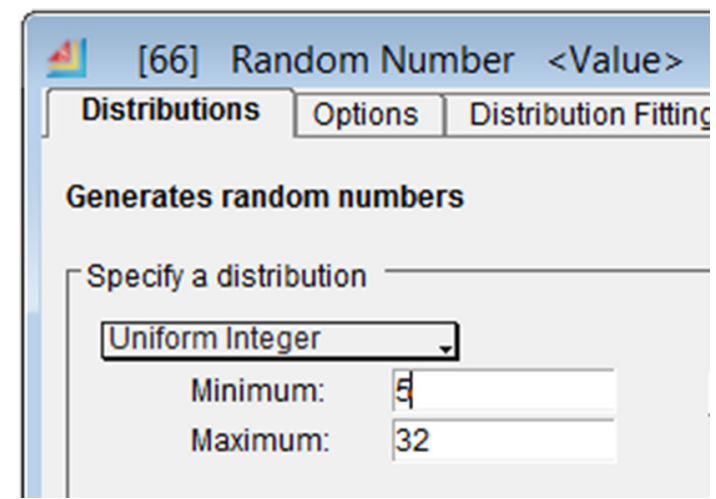

Fig. 6 Dialogue of the block „Random Number“ and its setting. Source: author

Loading the loading of a pallet on the forks of a forklift truck. Data is entered into this block via the " $D$ " connector, Fig. 10, from the "Random Number" (set the time range of activity). The time of this activity is set in the interval 3-5 s.

Transport 1 the movement of a forklift with a pallet. Data is entered into this block via the " $\mathrm{D}$ " connector from 
Fig. 7 Blocks "Resource Item-Bach". Source: author
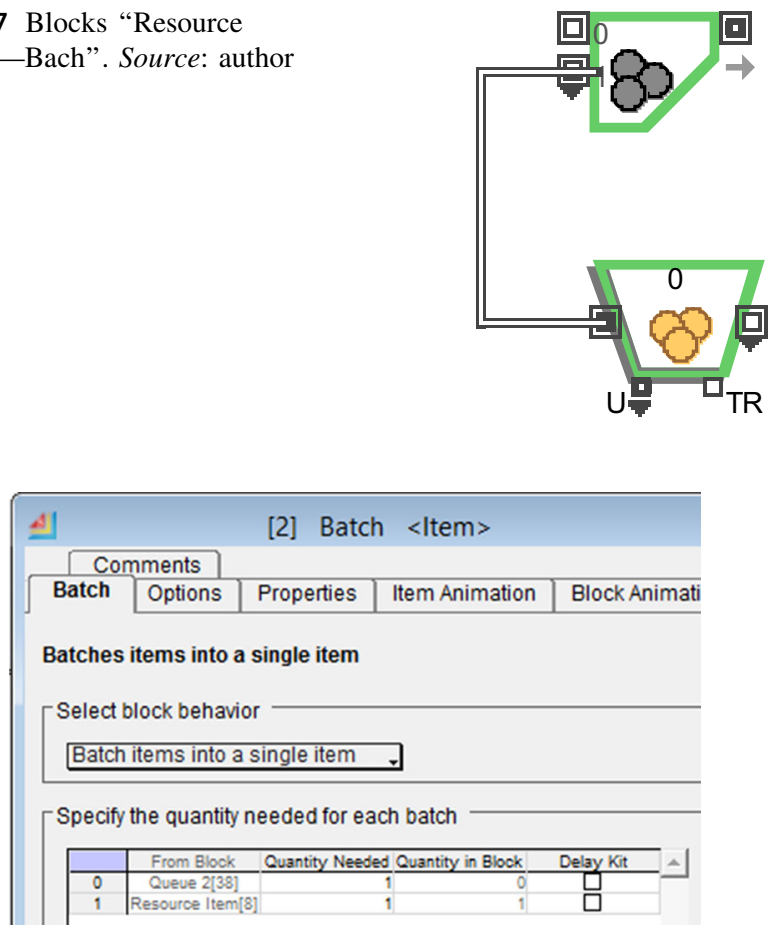

Fig. 8 Dialogue of the block „Bach“ and its setting. Source: author

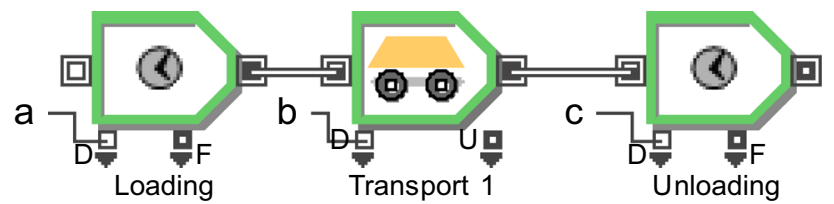

Fig. 9 Blocks „Activity Loading-Transport Move-Activity Unloading". Source: author

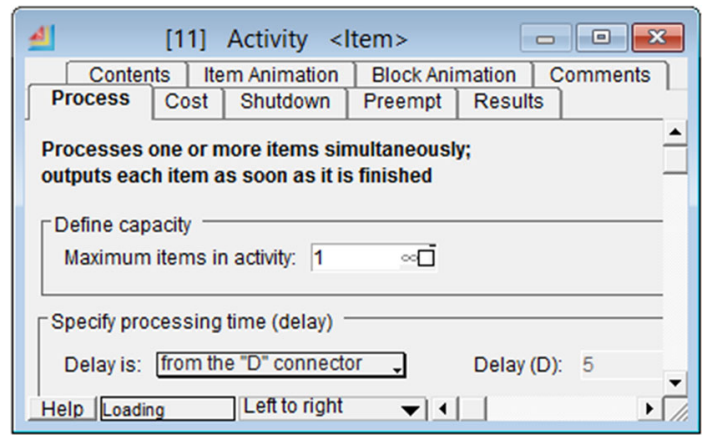

Fig. 10 Dialogue of the block „Activity Loading“ and its setting. Source: author

the "Random Number" too. The time of this activity is set in the interval 10-20 s.

Unloading the unloading of a pallet from the forks of a forklift truck. Data is entered into this block via the "D" connector from the "Random Number" too. The time of this activity is set in the interval $3-5 \mathrm{~s}$.
The last group of blocks is "Unbach-Activity Acceptance/Queue 3-Exit/ Transport Transport 2", Fig. 11. The block Unbatch divides the one into two parts: a pallet and a forklift, in simulation. The palette goes into the block Acceptance. The time of this activity is constant, $10 \mathrm{~min}$. The forklift returns to the loading place through the block Transport 2. Data is entered into this block via the "D" connector from the "Random Number" too. The time of this activity is set in the interval 10-15 s. The block Exit represents the output of the requirements, the number of pallets that were accepted to warehouse. The block "Discrete Event" draws graphs of the simulation performance from the input values and it writes the values of the monitored inputs to a table.

\subsection{Simulation experiments and simulation analysis}

After setting the simulation model, its usage goes on for the aim of examination of the activity of the system. Several experiments were performed on the simulation model. This article presents the results of 3 experiments.

The simulation simulates the activity of the system during $240 \mathrm{~min}$ (time of work shift for receipt of stocks).

The entry into the simulation model was 5 vehicles with loaded pallets and one forklift.

EXP_1: In the first experiment, 88 pallets had to be unloaded from five vehicles. There were 18 pallets in the first vehicle, 29 in the second vehicle, 5 in the third vehicle, 7 pallets in the fourth vehicle and 29 pallets in the fifth vehicle. In $176 \mathrm{~min}$, all pallets were unloaded and accepted, Fig. 12.

EXP_2: In the second experiment, 128 pallets had to be unloaded from five vehicles. There were 20 pallets in the first vehicle, 26 pallets in the second vehicle, 26 pallets in the third vehicle, 29 pallets in the fourth vehicle and 27 pallets in the fifth vehicle. In $188 \mathrm{~min}$, all pallets were unloaded and accepted. Figure 13 shows the process of unloading pallets from vehicles.

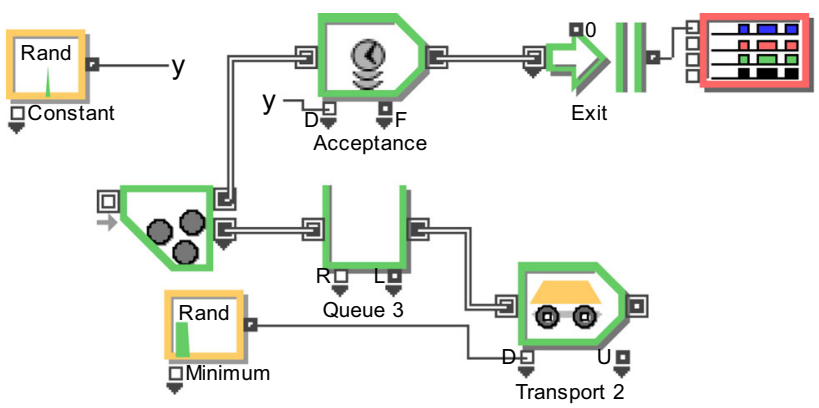

Fig. 11 Blocks is "Unbach-Activity Acceptance/Queue 3-Exit/ Transport Return Move". Source: author 


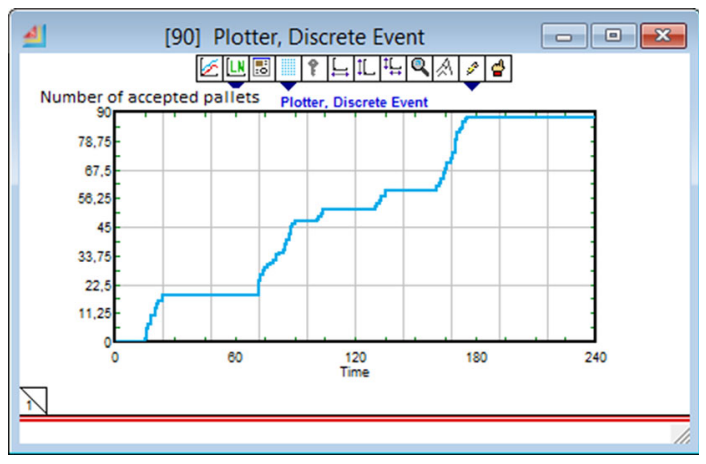

Fig. 12 EXP_1: The process of unloading vehicles until pallets acceptance. Source: author

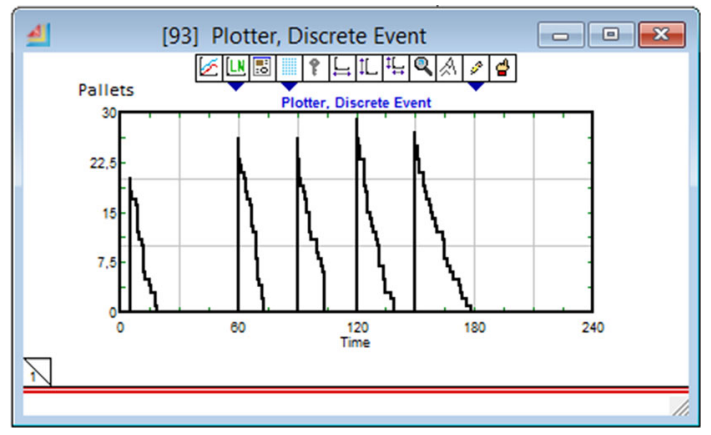

Fig. 13 EXP_2: The process of unloading vehicles. Source: author

EXP_3: In the third experiment, 99 pallets had to be unloaded from five vehicles. In the first vehicle, there were 10 pallets, in the second vehicle, there were 30 pallets, in the third vehicle, there were 17 in the fourth vehicle 20 pallets and the fifth vehicle 22 pallets. All pallets were unloaded and accepted in $174 \mathrm{~min}$. Figure 14 shows the process of unloading pallets from vehicles until pallets acceptance.

The results of the individual experiments are summarized in Table 1.

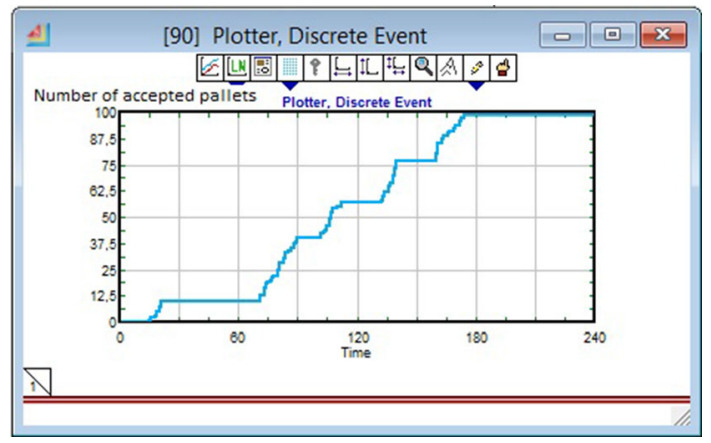

Fig. 14 EXP_3: The process of unloading vehicles until pallets acceptance. Source: author

\section{Discussion}

The analysis showed that a maximum of 5 means of transport must be unloaded during the working day. For this reason, simulations were performed for 5 vehicles. The number of pallets in the vehicle was the input value from the "Random Number" block set in the interval 5-32, as shown in Fig. 6.

By a more detailed examination of the results of the experiments, the indicators were determined, Table 2 :

A: unloading time 5 vehicles.

B: percentage of unloading time of the total duration of the activity.

C: percentage of the total duration of the activity of $240 \mathrm{~min}$.

D: average unloading time of 1 pallet (after rounding to whole seconds).

Table 2 shows that the indicator D corresponds to the values that were measured in operation. It can be stated that the results obtained from the simulation verified the results obtained by measuring the duty cycle.

Figure 15 shows the number of generated number of pallets in all experiments. As can be seen from Fig. 15, the maximum frequency of 3 was 29 .

Based on the results of both in-service analysis and simulation, it can be concluded that the simulation model and the results of further experiments can be beneficial for society. The results are a suitable basis for creating a suitable operational tool, which can be use, e.g. for planning the arrival and delivery of vehicles for loading. It is possible to change the model variables, in case they change even in real conditions (increase in the number of vehicles to be unloaded, increase or decrease in the number of forklifts, change in the length of the working cycle path). After small modifications, the mentioned model is also applicable for mirror activity, loading vehicles, e.g. during shipping.

Before implementing any change to the system, the authorized persons should make this change based on data obtained by simulation (verification of several variants of the change) and assess their acceptability based on several criteria (functionality, performance or reliability).

\section{Conclusion}

The warehousing process has an irreplaceable place in the company's logistics system and supply chain. Proper and efficient implementation of logistics activities in warehouses is one of its benefits. The article is devoted to simulations of selected logistics activities in the 
Table 1 The simulation results for a simulated time of $240 \mathrm{~s}$. source:author

\begin{tabular}{lccccc}
\hline & Truck 1 & Truck 2 & Truck 3 & Truck 4 & Truck 5 \\
\hline EXP_1 & 18 & 29 & 5 & 7 & 29 \\
Number of pallets & 7 & 18 & 3 & 3 & 15 \\
Unloading time (min) & & 176 & & \\
Time of whole activity (min) & 20 & 26 & 26 & 29 & 27 \\
EXP_2 & 14 & 13 & 14 & 19 & 26 \\
Number of pallets & & 188 & & \\
Unloading time (min) & & & & \\
Time of whole activity (min) & 10 & 30 & 17 & 20 & 22 \\
EXP_3 & 6 & 19 & 11 & 10 & 13 \\
Number of pallets & & & 174 & \\
Unloading time (min) & & & & \\
Time of whole activity (min) & & & &
\end{tabular}

Table 2 Specified indicators. Source: author

\begin{tabular}{llll}
\hline Indicators & EXP_1 & EXP_2 & EXP_3 \\
\hline A (min) & 46 & 86 & 59 \\
B (\%) & 26 & 46 & 34 \\
C (\%) & 74 & 78 & 73 \\
D (s) & 32 & 41 & 36 \\
\hline
\end{tabular}

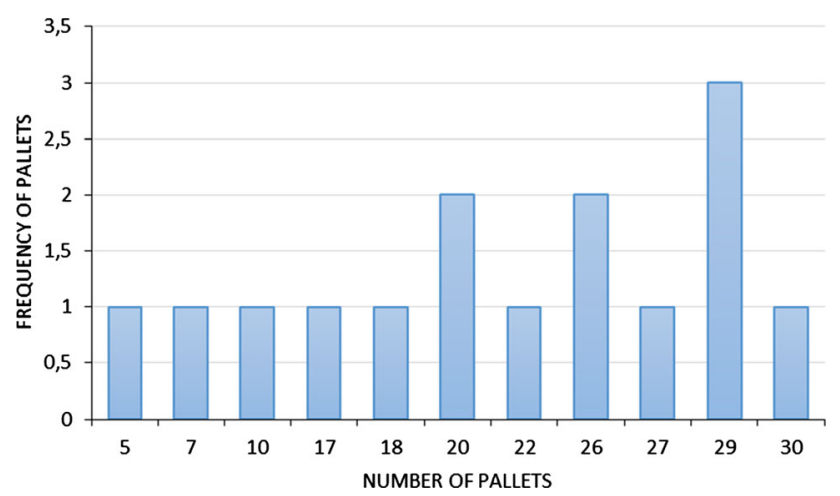

Fig. 15 Number of pallets. Source: author

warehouse-receipt of goods to the warehouse. The main benefit, novelty, of the article is the simulation of a selected activity for a specific company's conditions. Several experiments were performed on the created simulation model, three of which were presented in the article. Input data to the simulation were obtained by analysis of this activity under operating conditions.

The simulation model is a useful support tool for decision-making in the warehouse based on the experiments conducted. By changing the input data in the existing model, it is possible to simulate activities without affecting the actual operation, respectively, without the existence of a real system. The experiments' results can be a suitable tool, e.g. to obtain the data needed for the decisionmaking process of several variants. Simulation of a larger number of system variants can indicate both positive and negative changes after an intervention in a system. As a result of applying the simulation and using a suitably selected simulation program, you are more con fi dent that the proposed solution is right for the organization, even before the actual implementation in actual conditions.

The following research will aim to create a simulation model for further work in warehouses in operation-the storage of goods. The future research will also be focused on creating a simulation model in another simulation tool, e.g. Plant Simulation. The results of experiments performed by created models will be analyzed and compared; the advantages and disadvantages of created models will be also determined.

Acknowledgements "This work is supported by the Scientific Grant Agency of the Ministry of Education, Science, Research, and Sport of the Slovak Republic and the Slovak Academy Sciences as part of the research project VEGA 1/0588/21: "The research and development of new methods based on the principles of modeling, logistics and simulation in managing the interaction of mining and backfilling processes with regard to economic efficiency and the safety of raw materials extraction “, a part of the VEGA Project 1/0797/20, “ Quantification of the impacts of the environmental burden on the regions of Slovakia on the health and social and economic system of the country " and is supported by the project of the Cultural and Educational Grant Agency of the Ministry of Education, Science, Research and Sport of the Slovak Republic and the Slovak Academy of Sciences project No. KEGA 006TUKE-4/2019, and is supported by the project of the EIT RM (European Institute of Innovation and Technology RawMaterials) project MineTALC - Backfill Mining Optimisation for Low- and Medium- Strength Deposits.

Open Access This article is licensed under a Creative Commons Attribution 4.0 International License, which permits use, sharing, adaptation, distribution and reproduction in any medium or format, as long as you give appropriate credit to the original author(s) and the source, provide a link to the Creative Commons licence, and indicate if changes were made. The images or other third party material in this 
article are included in the article's Creative Commons licence, unless indicated otherwise in a credit line to the material. If material is not included in the article's Creative Commons licence and your intended use is not permitted by statutory regulation or exceeds the permitted use, you will need to obtain permission directly from the copyright holder. To view a copy of this licence, visit http://creativecommons. org/licenses/by/4.0/.

\section{References}

1. Chayaphum, A., Supsombo on, S., \& Butrat, A. (2019) The optimal number of reach trucks and order picker trucks in warehouse determining using simulation. In RI2C 2019-2019 research, invention, and innovation congress: Conference proceeding: Arnoma Grand Hotel Bangkok, Bangkok; Thailand. Institute of Electrical and Electronics Engineers Inc. https://doi. org/10.1109/RI2C48728.2019.8999936.

2. Baker, P., \& Canessa, M. (2009). Warehouse design: A structured approach. European Journal of Operational Research, 193, 425-436.

3. Gu, J., Goetschalckx, M., \& McGinnis, L. F. (2010). Research on warehouse design and performance evaluation: A comprehensive review. European Journal of Operational Research, 203, 539-549.

4. De Koster, R., Le-Duc, T., \& Roodbergen, K. J. (2007). Design and control of warehouse order picking: A literature review. European Journal of Operational Research, 187, 481-501.

5. Šaderová, J. (2019). Design of a storage system for a part of the distribution warehouse by applying the logistics principles. CLC 2018 Carpathian Logistics Congress: Logistics, distribution, transport and management (pp. 855-860). Tanger.

6. Cardona, L. F., Soto, D. F., Rivera, L., \& Martínez, H. J. (2015). Detailed design of fishbone warehouse layouts with vertical travel. International Journal of Production Economics, 170, 825-837.

7. Kłodawski, M., Jacyna, M., Lewczuk, K., \& Wasiak, M. (2017). The issues of selection warehouse process strategies. Procedia Engineering, 187, 451-457.

8. Saderova, J., Marasova, D., \& Gallikova, J. (2018). Simulation as logistic support to handling in the warehouse: Case study. TEM Journal, 7, 112-117. https://doi.org/10.18421/TEM71-13.

9. Burinskiene, A., Lorenc, A., \& Lerher, T. (2018). A simulation study for the sustainability and reduction of waste in warehouse logistics. International Journal of Simulation Modelling, 17(3), 485-497.

10. Rosova, A., Behun, M., Khouri, S., Cehlar, M., Ferencz, V., \& Sofranko, M. (2020). Case study: The simulation modeling to improve the efficiency and performance of production process. Wireless Networks. https://doi.org/10.1007/s11276-020-02341-z.

11. Straka, M., Malindzakova, M., Rosova, A., et al. (2016). The simulation model of the material flow of municipal waste recovery. Przemysl Chemiczny, 95(4), 773-777.

12. Sofranko, M., \& Zeman, R. (2014). Simulation of pipeline transport backfill mixtures. In ICCC 2014. 15th International Carpathian Control Conference (ICCC) (pp. 578-583).

13. Malandria, C., Briccolia, M., Mantecchinia, L., \& Paganellia, F. (2018). A discrete event simulation model for inbound baggage handling. Transportation Research Procedia. https://doi.org/10. 1016/j.trpro.2018.12.008.

14. Janic, P., Jadlovska, S., Zapach, J., \& Koska, L. (2019). Modeling of underground mining processes in the environment of MATLAB/Simulink. Acta Montanistica Slovaca, 24(1), 44-52.
15. Onofrejova, D., Janekova, J., Grincova, A., \& Soltysova, Z. (2020). Simulation and evaluation of production factors in manufacturing of fireplaces. International Journal of Simulation Modelling, 19, 77-88. https://doi.org/10.2507/ijsimm19-1-504.

16. Marasova, M., Saderova, J., \& Ambrisko, L. (2020). Simulation of the use of the material handling equipment in the operation process. Open Engineering, 10, 216-223. https://doi.org/10. 18421/TEM71-13.

17. Fedorko, F., Molnár, V., \& Mikušová, M. (2020). The use of a simulation model for high-runner strategy implementation in warehouse logistics. Sustainability. https://doi.org/10.3390/ su12239818.

18. Straka, M., Saderova, J., Bindzar, P., et al. (2019). Computer simulation as a means of efficiency of transport processes of raw materials in relation to a cargo rail terminal: A case study. Acta Montanistica Slovaca, 24(4), 307-314.

19. Bardzinski, P. J., Krol, R., \& Jurdziak, L. (2019). Empirical model of discretized copper ore flow within the underground mine transport system. International Journal of Simulation Modelling, 18, 279-289. https://doi.org/10.2507/ IJSIMM18(2) 473.

20. Knapcikova, L., Behunova, A., \& Behun, M. (2020). Using a discrete event simulation as an effective method applied in the production of recycled material. Advances in Production Engineering \& Management, 15(4), 431-440.

21. Rosova, A. (2007). Logistics costs of enterprise. Acta Montanistica Slovaca, 12(2), 121-127.

22. Behun, M., Kascak, P., Hrabcak, M., Knapcikova, L., \& Sofranko, M. (2020). Investigation of sustainable geopolymer composite using automatic identification technology. Sustainability, 12(16), 6377. https://doi.org/10.3390/su12166377.

23. Saderova, J. (2014). Warehousing logistics. Technical University of Kosice.

24. Straka, M., Lenort, R., Khouri, S., \& Feliks, J. (2018). Design of large-scale logistics systems using computer simulation hierarchic structure. International Journal of Simulation Modelling, 17(1), 105-118.

25. Perakovic, D., Behunova, A., \& Knapcikova, L. (2020). Analysis of product configurators used in the mass customization production. Acta Logistica, 7(3), 195-200.

26. Straka, M., Rosova, A., et al. (2018). Principles of computer simulation design for the needs of improvement of the raw materials combined transport system. Acta Montanistica Slovaca, 23(2), 163-174.

27. Saderova, J., Rosova, A., Kacmary, P., Sofranko, M., et al. (2020). Modelling as a tool for the planning of the transport system performance in the conditions of a raw material mining. Sustainability. https://doi.org/10.3390/su12198051.

Publisher's Note Springer Nature remains neutral with regard to jurisdictional claims in published maps and institutional affiliations. 


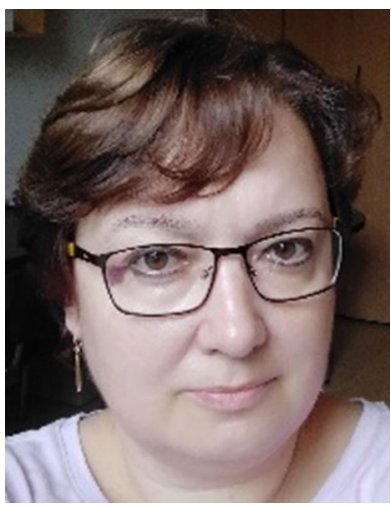

Janka Saderova is an Associate Professor at the Institute of Logistics and Transport, Faculty of Mining, Ecology, Process Control and Geotechnologies at the Technical University of Kosice. She finished engineering study in 1994. Ph.D. study finished in 1998 and habilitation finished in 2017 in the scientific field Logistics. Her research interests are in the area of simulation, modelling of logistics and transport processes and storage logistics. She has published over 50 scientific papers in journals for variety of academic journals.

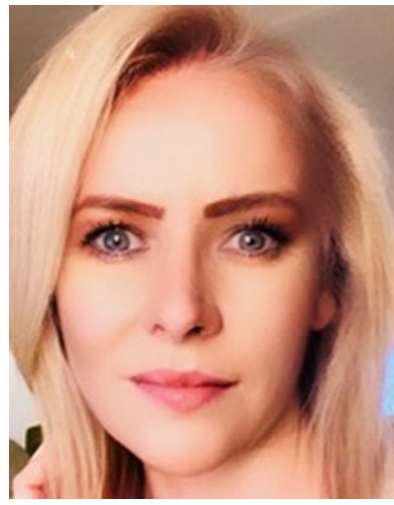

Andrea Rosova is an Associate Professor at the Institute of Logistics and Transport, Faculty of Mining, Ecology, Process Control and Geotechnologies at the Technical University of Kosice. She finished engineering study in 2000. Ph.D. study finished in 2006 and habilitation finished in 2013 in the scientific field Logistics. Her research interests are in the area of simulation, modelling of logistics processes, commercial logistics, measurement and evaluation of logistics performance enterprise. She has published over 150 scientific papers in journals for variety of academic journals.

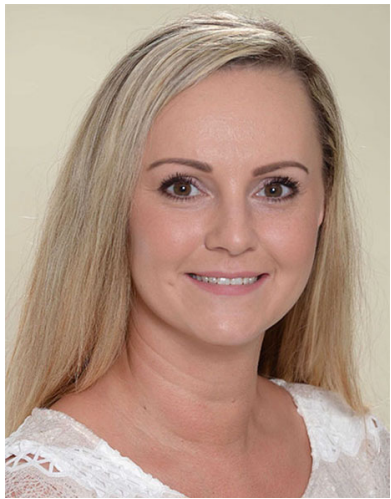

Annamaria Behunova is assistant professor in the field of Industrial Engineering, she works at the Institute of Earth Resources, Faculty of Mining, Ecology, Process Control and Geotechnologies and Department of Industrial Engineering and Informatics at the Faculty of Manufacturing Technologies with a seat in Presov. Her research is focused on exploring the impact of modern information technologies on changing the strategy of manufacturing enterprises. The introduction of mass customization and therefore the focus on the final customer represents a wide range of consumer needs and requirements that ultimately result not only in the productivity of the production enterprise but also in the associated production costs. She has a wealth of practical experience on the position of the financial manager and lecturer leader.

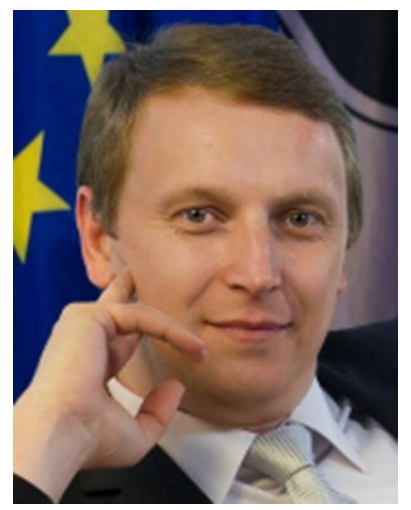

Marcel Behun is the Quaestor of Technical University of Kosice. As a part of his pedagogical and scientific research activities, he works at the Faculty of Mining, Ecology, Process Control and Geotechnologies. He deals with process management, economics and controlling in his pedagogical practice. His scientific and research activity is also focused on the field of mineral and building materials, the efficiency of production and non-production processes, the management of innovations in the manufacturing sector, the controlling of objects management, the quantification of economic and environmental impacts on the environment through the use of secondary raw materials, logistics processes in the manufacturing sector. $\mathrm{He}$ is the author of more than 50 scientific publications.

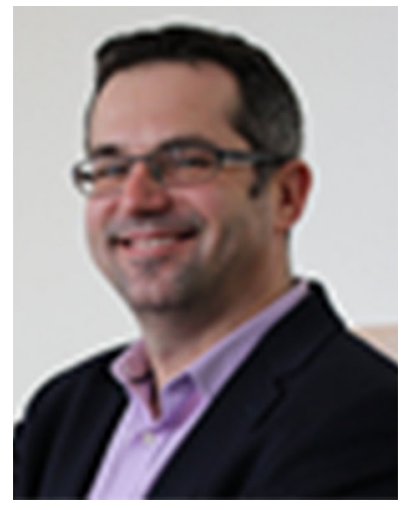

Marian Sofranko is an Associate Professor at the Institute of Earth Resources, Faculty of Mining, Ecology, Process Control and Geotechnologies at the Technical University of Kosice. He finished engineering study in 2000. He is graduate (2004) of EGEC (European Geotechnical and Environmental Course). Ph.D. study finished in 2006 and habilitation finished in 2016. His research interests are in the area of mining and safety of mine. He is the investigator of several research and application projects in this field of research. He has published over 60 papers in journals such as Energies, Sustainaibility, International Journal of Mining and Mineral Engineering, Inzynieria Mineralna, Scientific Journal Metallurgy, E\&M Economics and Management, International Scientific Journal Acta Montanistica Slovaca, Holistic Approach to Environment and others.

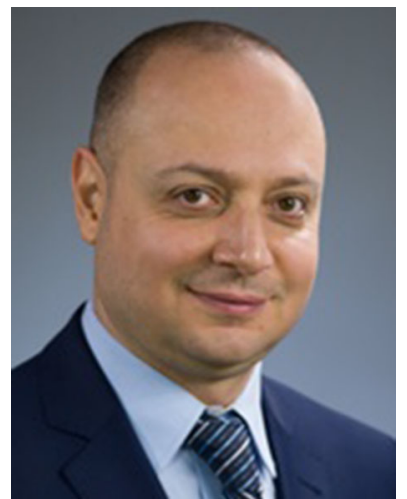

Samer Khouri is an Associate Professor at the Institute of Earth Resources, Faculty of Mining, Ecology, Process Control and Geotechnologies at the Technical University of Kosice. Science, education and expertise activities, covering widerange processes which include obtaining and processing of Earth resources, With the Ph.D. in obtaining and processing of Earth resources, he currently focuses in his research on Using the information technology in the obtaining and use of the earth's resources with focus on mining undertakings, In his work he has so far published over 90 articles for variety of academic journals. 